\title{
The First Family Cluster of COVID-19 in Bangladesh- Enigma in Developing Country
}

\author{
MR AMIN $^{\mathrm{a}}$, M SHARIF $^{\mathrm{b}}$, MA FAIZ $^{\mathrm{c}}$
}

\begin{abstract}
Summary:
Currently 221 countries of the globe is affected with COVID19 pandemic caused by a novel corona virus naming SARSCoV-2 and leads to more than 4000000 confirmed cases and more than 300000 death already. The South East Asia regions have many LMIC status where the health system is disorganized and less prepared than what it should be. Although India and Pakistan started to react against the pandemic with multiple strategy to combat the bloom of the epidemic, Bangladesh was relaxing as there were lack of confirmation of cases and although the country has prolonged period of time to combat the pandemic situation,
\end{abstract}

\section{Background:}

The novel corona virus SARS CoV 2 leads rise to COVID-19 infection and resulted in pandemic declared by WHO. ${ }^{1}$ Currently 221 countries of the globe is affected with more than 4000000 confirmed cases and more than 300000 death. ${ }^{1,2}$ Although the pandemic started at the wet market of Wuhan, capital of Hubei province of China as the niche of infection, the expansion around the globe quickly shifted toward Europe and USA where the epicenter is now well established. Although China had faced the initial storm with more than 80000 cases and more than 3000 death, the containment process and mitigation leads to a successful control status ${ }^{3}$. The next hit apparently spreads to Iran, Italy and the USA and all Europe countries who ignores the infectiousness and transmissibility of SARS CoV 2 and paid the price with huge numbers of cases and death. Although the health system of developed country is capable to recover from the deep impact of the pandemic, it becomes biggest worry how the developing countries and LMIC of globe would deal this apparently seems

a. Md Robed Amin, Professor of Medicine, Dhaka Medical College

b. Mohiuddin Sharif, Indoor Medical Officer, Dhaka Medical College

c. M A Faiz, Professor of Medicine, Former Director General of Health service

Address of Correspondence: Prof. Md. Robed Amin, Professor of Medicine, Room no 502, Department of Medicine, Dhaka Medical College and Hospital 2, e-mail-robedamin@yahoo.com it was not proactive from the beginning. Inappropriate screening at entry, poor quarantine process and gross lack of infection prevention and control measure leads to observe the confirmed cases to develop one by one. Even in this conservative testing approach of Bangladesh, a family of cluster (6 members) of confirmed COVID 19 was observed with development of huge question in health care system.

Key words: Pandemic, COVID-19, Family cluster, Developing.

(J Bangladesh Coll Phys Surg 2020; 38: 141-144) DOI: https://doi.org/10.3329/jbcps.v38i0.47344

tame virus with crude fatality below 3 percent ${ }^{4}$. The south east asia regions have many LMIC status where the health system is disorganized and less prepared than what it should be. Although India and Pakistan started to react against the pandemic with multiple strategy to combat the bloom of the epidemic, Bangladesh was relaxing as there were lack of confirmation of cases. There was lack of proactivity in Bangladesh due to absence of case and WHO China joint commission report related schematic management was not completely observed. The entry point through air, sea, railway and road remain open for travelers and thousands of peoples everyday arrives through these entry points with big porosity. Inappropriate screening at entry, inadequate quarantine process and gross lack of infection prevention and control measure leads to observe the confirmed cases to develop one by one. The conservative approach of testing is making things more complex and make heath care workers blind folded to this new evolving mutated respiratory pathogen. Even in this conservative approach, a family of cluster (6 members) of confirmed COVID-19 is observed in Bangladesh with development of huge question in health care system

\section{Vignette:}

Mr. X (A H), 36-year- old Bangladeshi male arrived in Bangladesh from Italy on March $7^{\text {th }}, 2020$ and landed at Dhaka Airport at 18:00 hrs. He was not using mask during travel. In the airport, he was screened through thermal scanner and provided one health related card at COVID- 


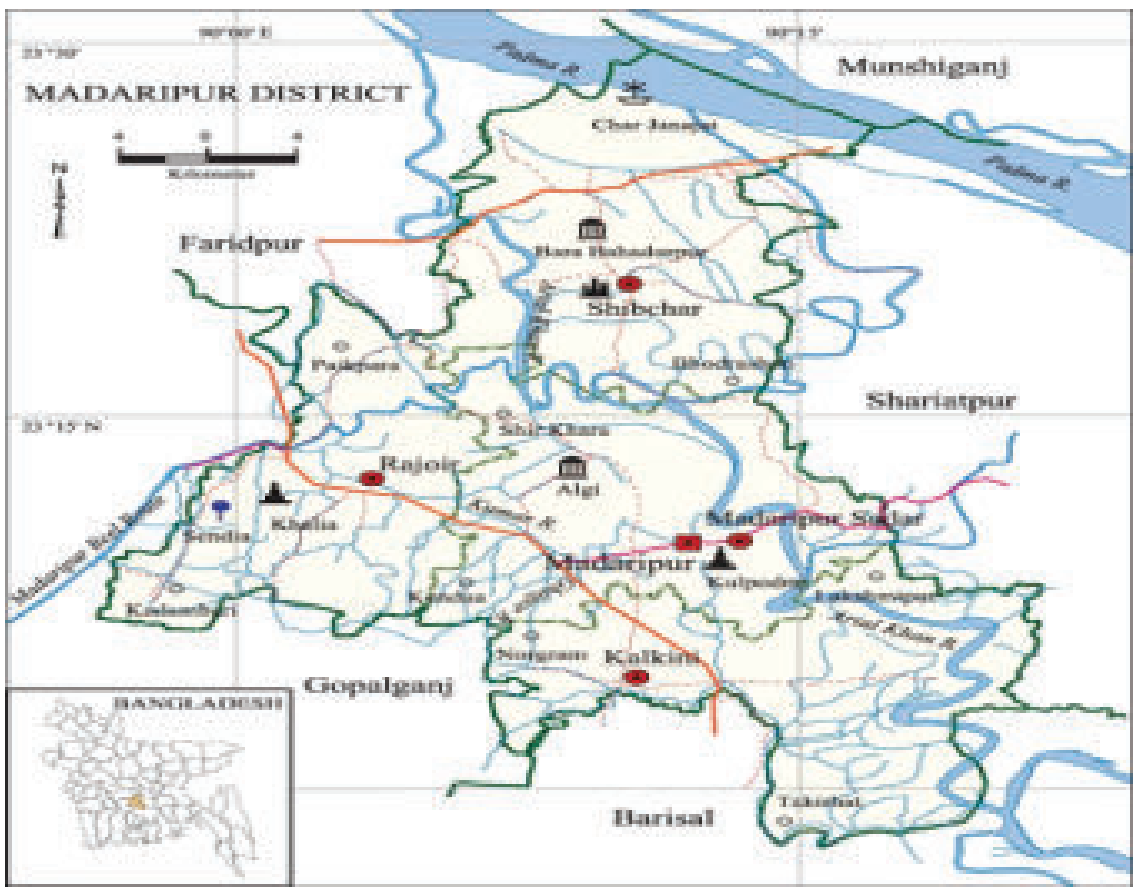

19 desk. He rented a private Car afterwards and traveled to his hometown, about $150 \mathrm{~km}$ from Dhaka, reaching there at $13.00 \mathrm{hrs}$ the next day. He was living with his family currently which includes his wife, son (2-Yearold) and daughter (6-Year-old). Two (2) days later, on March $8^{\text {th }}, 2020$ he developed fever, cough and low back pain. He tried few times of the hotline number provided in the health card but found busy. So, with these complaints, he went to upazilla health complex (UZHC) where he was attended by a doctor unprotected and not using mask who prescribed some general medications and advised him to go home.

During the next five (5) days, due to his symptoms of fever, cough and low back pain not getting better and showing no signs of improvement, he decided to travel towards Dhaka in a public transport (Bus) on March $13^{\text {th }}, 2020$ at $12.00 \mathrm{hrs}$. He reached his uncle's house at Hazaribag, Dhaka where he had lunch and took a brief rest period before arriving in the emergency department (ED) of Dhaka Medical College Hospital at17.00 hrs. After receiving a ticket from the ED, he was sent to Room 7 and then from Room 7, he was transferred to Ward 701 without any protective mask for respiratory droplet. In Ward 701, at first an Intern asked about his complaints, the patient gave his history about how he arrived in Bangladesh from Italy, went to his hometown and afterwards, feeling symptoms of fever, cough and low back pain, the On-Duty Intern referred to a senior IMO (Indoor medical officer).

Now, at first Indoor medical officer (IMO) analyzed the history of the patient and examined thoroughly. On examination, IMO found out, $\mathrm{BP}$ is $100 / 80 \mathrm{mmhg}$, pulse is 88 /minutes, temperature is $100^{\circ} \mathrm{F}$, clear lungs, no abnormality detected in examining heart, abdomen soft and non-tender. The patient complaining about his low back pain seems mechanical in nature. Afterwards, IMO prescribed him paracetamol tablets and called IEDCR (Institute of epidemiology, disease control and research) who is the center of control of pandemic COVID -19 in Bangladesh to inform about patient's detailed history. They responded quickly with IMO about their decision and instructed him to collect the patient's detailed address and to send him home. The IEDCR would contact the patient afterwards at a convenient time. At the same time, IMO sent this patient history to unit head (Professor of Medicine) and Departmental Head.

As per the advice of unit Head, IMO instructed the patient, Mr. X to remain isolated and use mask while moving and also told him to fully communicate and cooperate with IEDCR when they contact him later to visit him. The team of IEDCR who were present in DMCH agreed to take some samples from the patient whom 
IMO described to the team in detail. Director of IEDCR then instructed IMO not to let the patient go back home to Hazaribagh and the team would take his samples and he would be put in isolation in the Kuwait-Maitri Hospital (a designated COVID-19 hospital) afterwards. IMO called the patient and found that he had just finished praying on the ground floor mosque of DMCH. IMO took the patient in a separate, isolated empty place and keep patient to wait in that isolated empty place for the IEDCR team to go in and collect samples from him.

In the meantime, IMO contacted the Director of Dhaka Medical College Hospital (DMCH) to arrange an ambulance to transfer the patient to Kuwait-Maitri Hospital. Half an hour later, the IEDCR team took the samples from the patient and the ambulance was arranged. Afterwards, at 19:30 PM, the designated ambulance of DMCH started the trip to Kuwait-Maitri Hospital carrying the patient, his brother along with the ambulance driver. The next day, the patient who was tested RT PCR was found to be SARS COV-2 positive.

Earlier when IMO was asking the patient about his family history, patient notified that his wife was also having symptoms of fever on March $10^{\text {th }}, 2020$ but his children was feeling healthy and fine. However, he did not take immediate steps to treat the fever of his wife nor did he bring his wife to Dhaka with him for initial treatment of her symptoms. On the next Saturday (14-03-2020) morning, when the IEDCR team reached Madaripur to the family's home, they observed that both the children also with symptoms of fever. So, the IEDCR team took the decision to take samples from all three (3) family members after their initial observation. The next day 15th March on Sunday, all the three (3) family members were also found positive RT-PCR for SARS COV-2 and brought to the Kuwait-Maitree Hospital in Dhaka where they were isolated. Till 1-04-2020, the full family remain in Kuwait Maitree hospital and all four family members were doing relatively fine. Then all of them were tested RT PCR negative on two samples within 24 hours and discharged from the hospital. They went to their village in shibchor, Madaripur and remain there. On $8^{\text {th }}$ April , a blood test was done and it was told that the wife has some problem oin blood test and hence nasopharyngeal swab taken from wife and her father and mother and it came positive in all of them. So his wife and wife's father and mother was advised for hospitalization in madaripur hospital. But the full family
(6 members-husband, wife, two kids, father and mother) decided to go to hospital. In hospital when the test was repeated, all of them were found positive. So again they were decided to stay in hospital for 14 days and lastly on $24^{\text {th }}$ April, they were found all negative and discharged from hospital to home.

\section{Discussion:}

The system of containment of this family cluster of highly infectious COVD-19 was below per standard. The airport of Bangladesh although porous had the tracking system in place. ${ }^{5}$ The COVID- 19 was in bloom in Italy when the patient arrived in Bangladesh and the institutional quarantine was not in place. As the patient was in pre symptomatic stage, the thermal scanner missed him as it is observed in other countries as well. ${ }^{6}$ He received a health card there but there was lack of information through verbal communication at the airport. The journey toward his home from Dhaka was 5 hours without any mask or personal hygiene issue which is an important factor of transmission. ${ }^{7} \mathrm{He}$ was completely careless at home environment where he was with his family. There was no social distancing, lack of use of mask, no hand wash or cough etiquette in family which is most important factor of preventing transmission. ${ }^{7}$ His children's are in playful age and moving around at ease for subsequent few days. During his early symptoms, he tried to call the hotline numbers which were found constantly engaged indicating the excessive occupancy of the lines and need for more standard operating procedure to communicate with health authority. The patient took health service from existing public health care centre (secondary care centre) where there was huge number of patients attended in outdoor (around 350 per day) and he took common line for his appointment to see the physician. The physician misses the epidemiological link (travel history) and let him move around at will 5,7 . The lack of information relating COVID-19 in physician in this secondary care is a big concern as there are huge numbers of home quarantine cases around Bangladesh and who may seek consultation from primary or secondary care health service. The long four days of unprotected status in his home is dangerous as it lead to transmit the virus to his family and surroundings and which was proved later as his wife become quickly symptomatic and later his both children become symptomatic within sphere of 5 days. His journey to Dhaka from his home was in public 
transport and the whole journey time is mask free and the public were in apposition with him. The public transport in our country is not in strict regulatory body and the passenger lists and log are completely absent. So for contact tracing, it's nearly impossible for our health system to get the close contact completely. ${ }^{8}$

At Dhaka, the patient stayed at his relative's home where he also possibly transmitted the disease. The IEDCR traced the relative's family but not the surroundings that were with him while he was moving around. The consultation of $\mathrm{DMCH}$ was a complete faulty to deal this infectious case. The emergency room is congested with huge patient and he was transferred to a different room where there were also lots of regular patients. There is no triage, emergency room and the observation room is having compete lack of infection and prevention control measure and the physicians are having no personal protective equipment even in this pandemic time ofCOVID-19. ${ }^{9}$ The observation room let this patient to go to indoor ward where he was shifted in crowd, used the common patients' lift and arrived at doctors' room which also seemed a large traffic at evening. No specific guidance by central authority for track system for this kind of patient was established. There was no system of protocol of isolation in place in general hospital like DMCH. The ambulance provided by the $\mathrm{DMCH}$ to transfer the patient to COViD-19 designated hospital is also not trained and lack of complete PPE and protocol. 9,10

The basic mitigation process for LMIC country like Bangladesh is quarantine, social distancing, personal hygiene like WASH and Cough etiquette for COVID$19^{9}$. There is deficiency in each of these components observed in this case series. The health care system is yet prepared to deal with highly infectious disease like COVID-19. The basic principle of infection prevention and control in hospital should be urgently implemented. All preventive process need to be addressed seriously in education (from primary education) and during lifestyle of every citizen.

The surprising thing of this family cluster was their bizarre test reports. The initial RT PCR positivity and discharge criteria was fulfilled according to WHO. But while they were in Madaripur, wife's father and mother get positive and possibly get the infection from wife as she was also positive. How she remains positive after such a long gap was a surprise and even more, when the 6 members family was in Madaripur hospital, all become positive. The prolonged positivity of RT PCR may not always indicate active viral replication rather fragments of viral proteins. But the positivity in parents from them also precludes the possibility of dormant virus in respiratory epithelium and hence reactivation or reinfection remain always in the card.

\section{Conclusion:}

This was the first family clusters of confirmed COVID19 in Bangladesh indicating local transmission of the pandemic from human to human. There are thousands of unprotected quarantine cases in community which are basically can act as time bomb in community with extensive community transmission. The WHO China commission recommendation for imported country need to be established as quickly as possible to combat the toll of pandemic in middle income country like Bangladesh. Otherwise we are waiting to see the disaster of the century in this land.

\section{References:}

1. World Health Organization. Novel coronavirus(2019nCoV):situationreport. Accessed May 16,2020.https:// www.who.int/ docs/default source/coronaviruse/ situationreports/20200204-sitrep-15-ncov.pdf

2. World Health Organization. Clinical management to severe acute respiratory infection when novel coronavirus $(\mathrm{nCoV})$ infection is suspected: interim guidance. Published January28, 2020. Accessed January 31, 2020. https://www. who.int/publications-detail/clinical-managementof-severeacute-respiratory-infection-when-novelcoronavirus(ncov)-infection-is-suspected

3. Wuhan Municipal Health Commission. Reportof novel coronavirus-infected pneumonia inChina. Published January 20, 2020.Accessed January31, 2020.http://wjw.wuhan. gov.cn/front/web/ showDetail/2020012009077

4. China National Health Commission. Update on the novel coronavirus pneumonia outbreak (Jan 24, 2020). Beijing: China National Health Commission, 2020. http:// www.nhc.gov.cn/xcs/yqfkdt/202001/ c5da49c4c5 bf4bcfb 320ec2036480627.shtml (accessed Jan 24, 2020).

5. https://iedcr.gov.bd/images/files/nCoV/leaflet $\% 20$ final $\%$ 20v4.pdf

6. https://www.cyprusprofile.com/en/articles/thermalcameras-at-airports-to-scan-for-covid-19-symptoms/

7. World health organization. Report of the WHO-China Joint Mission on Coronavirus Disease 2019 (COVID-19) 28 February 2020 Report

8. Dhaka Tribune, Covid-19: New integrated control room, 2 fresh cases Kamrul Hasan Published at 12:29 am March 18 th, 2020

9. World health organization ,Shortage of personal protective equipment endangering health workers worldwide 3 March 2020 ,News release, Geneva

10. Ambulance drivers in times of Coronavirus: don't be silly .By Emergency Live Last updated Mar 9, 2020 